Article

\title{
Identification of Secondary Metabolites from Aspergillus pachycristatus by Untargeted UPLC-ESI-HRMS/MS and Genome Mining
}

\author{
Bruno Perlatti ${ }^{1, *,+}\left(\mathbb{D}\right.$, Nan Lan ${ }^{1,+}$, Yongying Jiang ${ }^{2}$, Zhiqiang An ${ }^{1}$ and Gerald Bills ${ }^{1}(\mathbb{D}$ \\ 1 Texas Therapeutic Institute, The Brown Foundation Institute of Molecular Medicine, University of Texas \\ Health Science Center at Houston, Houston, TX 77054, USA; nan.lan@uth.tmc.edu (N.L.); \\ zhiqiang.an@uth.tmc.edu (Z.A.); gerald.f.bills@uth.tmc.edu (G.B.) \\ 2 Institute for Applied Cancer Science, M.D. Anderson Cancer Center, Houston, TX 77054, USA; \\ yjiang4@mdanderson.org \\ * Correspondence: bruno.perlatti@uth.tmc.edu \\ + These authors contribute equally to the work.
}

Received: 15 January 2020; Accepted: 14 February 2020; Published: 18 February 2020

\begin{abstract}
Aspergillus pachycristatus is an industrially important fungus for the production of the antifungal echinocandin B and is closely related to model organism A. nidulans. Its secondary metabolism is largely unknown except for the production of echinocandin B and sterigmatocystin. We constructed mutants for three genes that regulate secondary metabolism in A. pachycristatus NRRL 11440 , and evaluated the secondary metabolites produced by wild type and mutants strains. The secondary metabolism was explored by metabolic networking of UPLC-HRMS/MS data. The genes and metabolites of $A$. pachycristatus were compared to those of $A$. nidulans FGSC A4 as a reference to identify compounds and link them to their encoding genes. Major differences in chromatographic profiles were observable among the mutants. At least 28 molecules were identified in crude extracts that corresponded to nine characterized gene clusters. Moreover, metabolic networking revealed the presence of a yet unexplored array of secondary metabolites, including several undescribed fellutamides derivatives. Comparative reference to its sister species, A. nidulans, was an efficient way to dereplicate known compounds, whereas metabolic networking provided information that allowed prioritization of unknown compounds for further metabolic exploration. The mutation of global regulator genes proved to be a useful tool for expanding the expression of metabolic diversity in $A$. pachycristatus.
\end{abstract}

Keywords: Aspergillus pachycristatus; metabolic networking; global regulators; LaeA; veA; mcrA

\section{Introduction}

Secondary metabolites from fungi are a plentiful and valuable source of molecules that exhibit a wide range of chemical structures and biological activities. Manipulation of culture media composition and genetic mutations can influence the metabolic outcome of culturing a fungus and expand overall numbers of detectable metabolites. However, recognition of effective combinations of parameters that will stimulate the biosynthesis of novel or cryptic metabolites often requires growing a strain in question in many different experiments, leading to cumbersome workflows and repeated encounters of the same compounds [1]. Development and application of efficient methods for molecular dereplication in complex samples with minimal sample work-up are needed to guide the decision-making process. One such method employs untargeted liquid chromatography coupled to tandem high-resolution mass spectrometry (LC-HRMS/MS) and takes advantage of both high-resolution monoisotopic mass measurements and MS/MS fragmentation profiles to generate data which can be used to detect and 
classify molecules within a single run [2,3]. The significant amounts of data generated are interrogated against databases to identify known substances without the need for purification of each individual component. These spectra can further be used as input for generation of molecular networks, clusters of known and unknown molecules linked based on similarities found in their MS and MS/MS spectra, thus allowing for the classification of a large number of molecules, including previously unidentified substances [4].

Aspergillus pachycristatus NRRL 11440 (= ATCC 58397) and its mutants, also previously referred to as $A$. nidulans var. roseus and Emericella rugulosa [5,6], have been used for industrial-scale production of echinocandin B, a lipohexapeptide used as starting material for the semisynthetic antifungal drug anidulafungin [7-9]. A draft genome sequence of A. pachycristatus NRRL 11440 revealed a remarkable similarity between $A$. pachycristatus and $A$. nidulans, a model organism that has had its secondary metabolism studied extensively during the past decade. The collection of studies aimed at understanding $A$. nidulans secondary metabolome has led to the discovery of at least 44 gene clusters responsible for the biosynthesis of over 100 secondary metabolites [10,11]. However, only a few secondary metabolites have been described for A. pachycristatus, including echinocandins and sterigmatocystin [5,7]. Recently we have determined that the LaeA (Apc.laeA) and VeA (Apc.veA) global regulatory system was operative in A. pachycristatus NRRL 11440 [12]. Disruption of genes encoding these key proteins negatively affected the production of echinocandin $\mathrm{B}$ and nearly abolished sterigmatocystin production. We also observed that Apc.laeA and Apc.veA were essential for normal conidiation and formation of ascomata in A. pachycristatus. These experiments focused exclusively on the echinocandin and sterigmatocystin pathways, but we recognized that these mutations also profoundly affected multiple secondary pathways in these mutant strains in a predictable and reproducible manner [12].

We hypothesized that by comparisons to a closely related reference species, viz. A. nidulans, as a genetic and metabolic database, we could quickly characterize a portion of the metabolome of $A$. pachycristatus while gaining a measurement of the extent of novelty available for further chemical exploration. Therefore, we aimed to interrogate the secondary metabolism of A. pachycristatus NRRL 11440 with previous data from the $A$. nidulans FGSC A4 metabolome and genome as a proxy to characterize its metabolites and tentatively attribute them to their corresponding gene clusters. These analyses provided new insights regarding the degree of divergence in secondary metabolism expected between sibling species of Aspergillus. We analyzed extracts from two modified wild-type strains and three mutant strains of NRRL 11440 with disruptions in three global regulator genes known to remodel Aspergillus secondary metabolism. These disrupted genes included laeA and veA, two global regulators of secondary metabolism in Aspergillus species [13-17], and $m c r A$, a recently discovered master transcription regulator of secondary metabolism [18].

\section{Results and Discussion}

\subsection{Metabolic Diversity in Aspergillus pachycristatus}

Five strains of $A$. pachycristatus, designated wt1, $\triangle A p c . l a e A, \triangle A p c . v e A$, wt3, and $\triangle A p c . m c r A$ (Figure S1, Table S1) were grown in the same set of culture conditions, and the crude extracts were analyzed by UPLC-HRMS/MS. The resulting chromatograms (Figure 1) were plotted on the same scale corresponding to a maximum peak height to highlight their differences. 


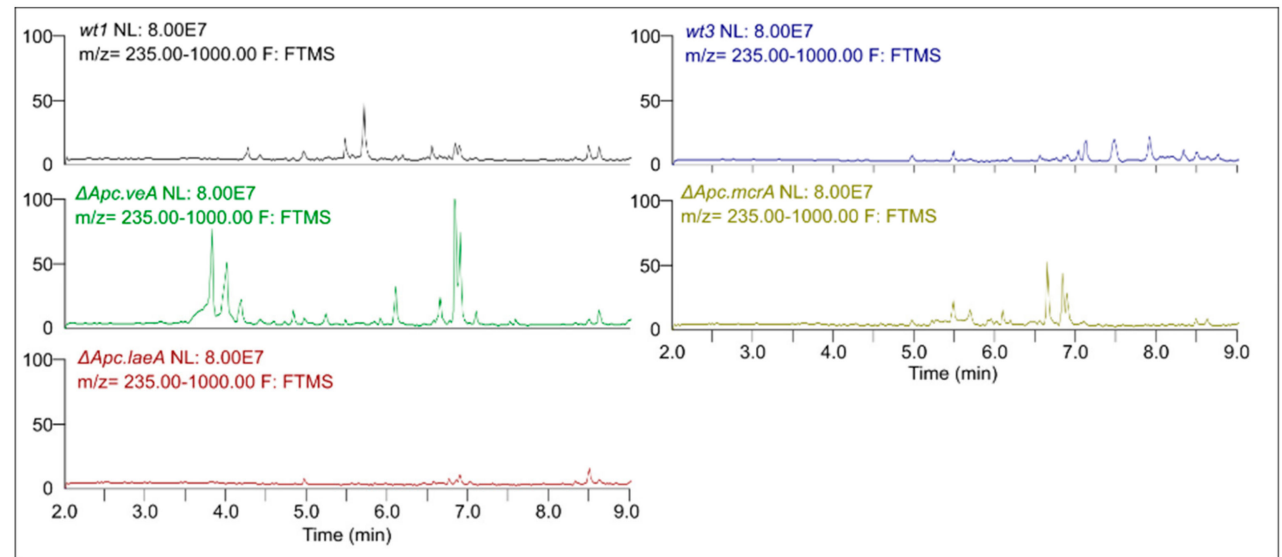

Figure 1. Representative UPLC-HRMS chromatograms obtained for extracts from wt1, $\triangle$ Apc.laeA, $\triangle A p c . v e A$, wt3, and $\triangle A p c . m c r A$ strains of $A$. pachycristatus NRRL 11440 grown in SMY medium.

Remarkable qualitative differences were evident among them indicating changes in secondary metabolism. It was possible to observe the appearance of several peaks in $\triangle A p c . v e A$ and $\triangle A p c . m c r A$ when compared to their respective parental strains, wt1 and wt3, helping to expand the array of detectable molecules. On the other hand, as we had observed in our previous experiments [12], the $\triangle A p c . l a e A$ mutant showed remarkable absence of peaks, with almost no detectable signals.

The raw MS data were submitted to the GNPS platform (https://gnps.ucsd.edu; ID=5b9e80c94f054e0d91f194be81594019) in order to build a molecular network containing the detected metabolites of $A$. pachycristatus. A total of 2183 different $\mathrm{MS}^{2}$ spectra collected from among the five samples were clustered in 920 nodes according to its MS $^{2}$ fragmentation. The databases in GNPS displayed positive matches for 11 of those nodes. Verification based on identity, HRMS monoisotopic mass deviation and $\mathrm{MS}^{2}$ spectra led to the confirmation of three of those secondary metabolites as 4, 14, and 21. The MS ${ }^{1}$ exact masses were compared with known A. nidulans secondary metabolites, which allowed the putative identification of 19 additional molecules (1-3, 5-13, 15-20) (Table 1). $\mathrm{MS}^{2}$ spectra were used to validate identified molecules when possible. Echinocandins were not detected by UPLC-HRMS/MS because the mass cutoff was set at $\mathrm{m} / \mathrm{z}=1000$, although HPLC-MS found echinocandins in extracts of all strains (Figure S2).

Table 1. Secondary metabolites identified from Aspergillus pachycristatus NRRL 11440.

\begin{tabular}{|c|c|c|c|c|c|c|}
\hline $\mathbf{N}^{\circ}$ & Molecule & R. Time & Exact Mass $[\mathrm{M}+\mathrm{H}]^{+}$ & $m / z$ Found & Error (ppm) & Class \\
\hline 1 & Alternariol $^{\mathrm{b}}$ & 4.08 & 259.0607 & 259.0603 & -1.5 & Polyketide \\
\hline 2 & F9775-A ${ }^{b}$ & 3.40 & 397.0923 & 397.0921 & -0.5 & Polyketide \\
\hline 3 & F9775-B ${ }^{b}$ & 3.91 & 397.0923 & 397.0920 & -0.8 & Polyketide \\
\hline 5 & Aspernidine $\mathrm{A}^{\mathrm{b}}$ & 7.25 & 400.2488 & 400.2487 & -0.3 & Prenylated alkaloid \\
\hline 6 & Aspernidine $\mathrm{B}^{\mathrm{b}}$ & 6.70 & 386.2331 & 386.2324 & -1.8 & Prenylated alkaloid \\
\hline 7 & Aspernidine $\mathrm{C}^{\mathrm{b}}$ & 7.29 & 414.2644 & 414.2638 & -1.5 & Prenylated alkaloid \\
\hline 9 & Aspercryptin $\mathrm{A} 2{ }^{\mathrm{b}}$ & 5.60 & 742.5443 & 742.5432 & -1.5 & Lipopeptide \\
\hline 10 & Antibiotic $1656 G^{b}$ & 6.40 & 584.4018 & 584.4023 & 0.9 & Lipopeptide \\
\hline 11 & Antibiotic $3127^{\mathrm{b}}$ & 5.58 & 542.3548 & 542.3557 & 1.6 & Lipopeptide \\
\hline 12 & Fellutamide $\mathrm{B}^{\mathrm{b}}$ & 5.68 & 556.3705 & 556.3706 & 0.2 & Lipopeptide \\
\hline 13 & Fellutamide $\mathrm{C}^{\mathrm{b}}$ & 5.47 & 558.3861 & 558.3860 & -0.2 & Lipopeptide \\
\hline 14 & Emericellamide $\mathrm{A}^{\mathrm{a}}$ & 6.64 & 610.4174 & 610.4177 & 0.5 & Cyclic lipopeptide \\
\hline
\end{tabular}


Table 1. Cont.

\begin{tabular}{|c|c|c|c|c|c|c|}
\hline $\mathbf{N}^{\circ}$ & Molecule & R. Time & Exact Mass $[\mathrm{M}+\mathrm{H}]^{+}$ & $m / z$ Found & Error (ppm) & Class \\
\hline 17 & Emericellamide $\mathrm{F}^{\mathrm{b}}$ & 6.89 & 624.4331 & 624.4332 & 0.2 & Cyclic lipopeptide \\
\hline 18 & Emericellamide $\mathrm{G}^{\mathrm{b}}$ & 5.90 & 582.3861 & 582.3862 & 0.2 & Cyclic lipopeptide \\
\hline 19 & Emericellamide $\mathrm{H}^{\mathrm{b}}$ & 7.08 & 638.4487 & 638.4488 & 0.2 & Cyclic lipopeptide \\
\hline 20 & Sterigmatocystin ${ }^{b}$ & 5.76 & 325.0712 & 325.0706 & -1.9 & Polyketide \\
\hline 21 & $\mathrm{~N}, \mathrm{~N}^{\prime}, \mathrm{N}^{\prime \prime}$-triacetylfusarinine ${ }^{\mathrm{a}}$ & 3.82 & 853.4189 & 853.4197 & 0.9 & $\begin{array}{l}\text { Hydroxamate } \\
\text { siderophore }\end{array}$ \\
\hline
\end{tabular}

${ }^{a}$ Compounds identified using GNPS database. ${ }^{b}$ Compounds identified by matching HRMS with known Aspergillus nidulans secondary metabolites. ${ }^{\mathrm{C}}$ It is not possible to distinguish between the two isomers in this case.

From the 920 nodes, the GNPS generated 38 network clusters containing two or more nodes. Of the 136 nodes used, 11 corresponded to molecules identified by GNPS or HRMS (Figure 2).

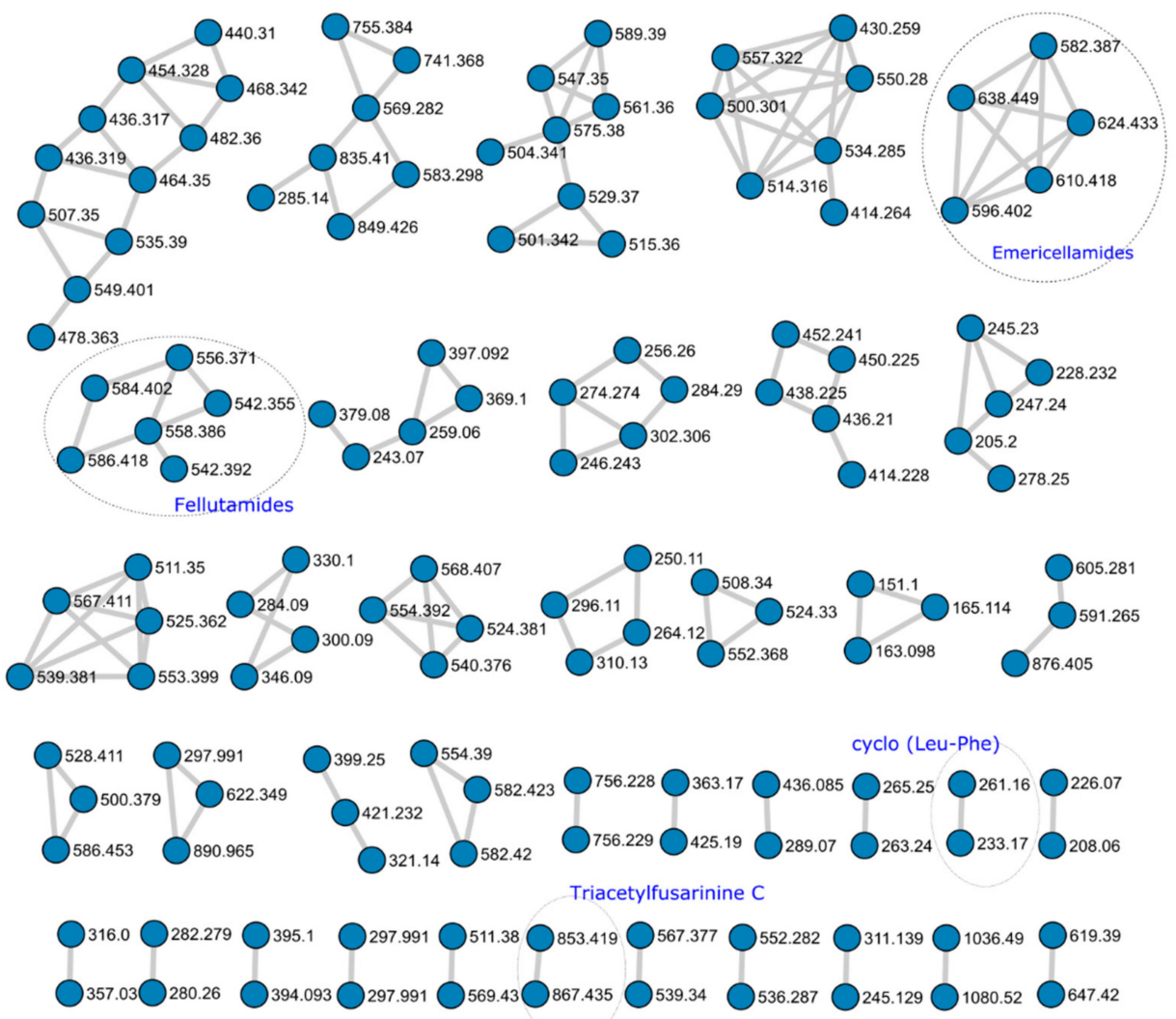

Figure 2. Metabolic Network cluster obtained from the UPLC-HRMS analysis of Aspergillus pachycristatus mutants grown in SMY medium showing network clusters with two or more nodes. Numbers represent the HRMS $\mathrm{m} / \mathrm{z}$ observed for each node. Circled clusters indicate molecules positively identified.

Two network clusters were further investigated to identify putative unknown nodes based on MS/MS fragment evaluation.

The GNPS database identified the molecule $\mathrm{N}, \mathrm{N}^{\prime}, \mathrm{N}^{\prime \prime}$-triacetylfusarinine (TAFC) based on $\mathrm{MS}^{1}$ and $\mathrm{MS}^{2}$ spectra (Figure S3). TAFC is a cyclic molecule composed of three $\mathrm{N}^{5}$-cis-anhydromevalonyl- $\mathrm{N}^{5}$-hydroxy- $\mathrm{N}^{2}$-acetyl-L-ornithine residues. Aspergillus nidulans, A. fumigatus and other Aspergillus species produce it as a major extracellular iron siderophore $[19,20]$. The TAFC network node was clustered with an unknown nodule showing remarkable similarity in $\mathrm{MS}^{2}$ fragmentation (Figure 2). The major difference arose from an increment of $\mathrm{m} / \mathrm{z}=14.0157 \mathrm{Da}$ in $\mathrm{MS}^{1}$ adducts, and $\mathrm{MS}^{2}$ evaluation indicated the presence of one extra methylene in one of the repeating units of the structure (22; Figure S4) The absence of an ion with $\mathrm{m} / \mathrm{z}=741.36$ suggested the presence of a $\mathrm{N}^{6}$-cis-anhydromevalonyl- $\mathrm{N}^{6}$-hydroxy- $\mathrm{N}^{2}$-acetyl-L-lysine Although there are a few examples of bacterial siderophores containing $-\mathrm{N}^{6}$-hydroxy- $\mathrm{N}^{2}$-acetyl-L-lysine [21-23], fungal siderophores have 
not been reported to incorporate this unit [24-27]. Further $\mathrm{MS}^{1}$ evidence suggested the presence of di- and tri- substituted units, as observed by the $\mathrm{MS}^{1}$ spectra of ions $\mathrm{m} / z=881$ (23) and $\mathrm{m} / z=895$ (24) showing the same clustered adduct ions in $\mathrm{MS}^{1}$, but they were not obtained with enough intensity to produce observable $\mathrm{MS}^{2}$ spectra (Figure S5). It is possible to infer that the substitution might be observed in any number of the three $\mathrm{N}^{5}$-cis-anhydromevalonyl- $\mathrm{N}^{5}$-hydroxy-L-ornithine residues, resulting in derivatives of $\mathrm{N}, \mathrm{N}^{\prime}, \mathrm{N}^{\prime \prime}$-triacetylfusarinine. To the best of our knowledge, derivatives bearing extra methylene units for this class of siderophore have not been reported.

Close inspection of $\mathrm{MS}^{1}$ and $\mathrm{MS}^{2}$ spectra and comparison with databases and literature enabled the identification of four fellutamide analogs in a constellation of six nodes, antibiotic 1656G (10; $m / z=584.402)$ antibiotic $3127(\mathbf{1 1} ; m / z=542.355)$, fellutamide B (12; $m / z=556.371)$ and fellutamide $\mathrm{C}(13 ; m / z=558.386)$. Fellutamides are tripeptides aldehydes obtained from Penicillium, Aspergillus, and Metulocladosporiella species that inhibit the eukaryotic proteasome [28-31]. The fellutamide C identified here is the same as identified by Lee and co-workers [28], and not the one characterized from a Metulocladosporiella species [31] that was later renamed fellutamide E [32].

Analysis of $\mathrm{MS}^{2}$ spectra of the four fellutamides showed a common fragment associated with peptides fragmentation mechanisms (Figure 3) that allowed us to propose putative structures for the two other unidentified nodes (25 and 26). Furthermore, manual curation of chromatograms permitted the identification of two other nodes with similar MS/MS fragmentation patterns (27 and 28), even though they were not grouped into the molecular network due to the settings used (Table 2). Their $\mathrm{MS}^{1}$ and $\mathrm{MS}^{2}$ spectra are shown in Figure S6.

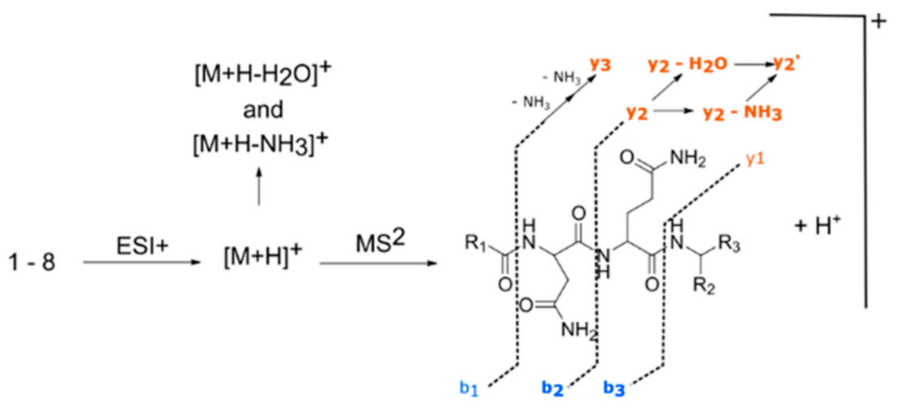

Figure 3. Description of molecular diversity for the different fellutamides observed.

Table 2. Fellutamide derivatives identified from Aspergillus pachycristatus NRRL 11440.

\begin{tabular}{|c|c|c|c|c|c|}
\hline $\mathbf{N}^{\circ}$ & Name & $\begin{array}{l}\text { Molecular } \\
\text { Formula }\end{array}$ & {$[\mathrm{M}+\mathrm{H}]^{+}$Ion } & R1 & R3 \\
\hline 10 & Antibiotic $1656 \mathrm{G}$ & $\mathrm{C}_{29} \mathrm{H}_{53} \mathrm{~N}_{5} \mathrm{O}_{7}$ & 584.4023 & $\mathrm{C}_{11} \mathrm{H}_{23} \mathrm{CH}(\mathrm{OH}) \mathrm{CH}_{2} \mathrm{CHO}$ & $i-\mathrm{Bu}$ \\
\hline 11 & Antibiotic 3127 & $\mathrm{C}_{26} \mathrm{H}_{49} \mathrm{~N}_{5} \mathrm{O}_{7}$ & 542.3557 & $\mathrm{C}_{9} \mathrm{H}_{19} \mathrm{CH}(\mathrm{OH}) \mathrm{CH}_{2} \mathrm{CHO}$ & $i-\operatorname{Pr}$ \\
\hline 12 & Fellutamide B & $\mathrm{C}_{27} \mathrm{H}_{49} \mathrm{~N}_{5} \mathrm{O}_{7}$ & 556.3706 & $\mathrm{C}_{9} \mathrm{H}_{19} \mathrm{CH}(\mathrm{OH}) \mathrm{CH}_{2} \mathrm{CHO}$ & $i-\mathrm{Bu}$ \\
\hline 13 & Fellutamide C & $\mathrm{C}_{27} \mathrm{H}_{51} \mathrm{~N}_{5} \mathrm{O}_{7}$ & 558.3860 & $\mathrm{C}_{9} \mathrm{H}_{19} \mathrm{CH}(\mathrm{OH}) \mathrm{CHEH} 2 \mathrm{OH}$ & $i-\mathrm{Bu}$ \\
\hline 25 & Fellutamide derivative 1 & $\mathrm{C}_{29} \mathrm{H}_{55} \mathrm{~N}_{5} \mathrm{O}_{7}$ & 586.4175 & $\mathrm{C}_{11} \mathrm{H}_{23} \mathrm{CH}(\mathrm{OH}) \mathrm{Cl} \mathrm{C}_{2} \mathrm{H} 2 \mathrm{OH}$ & $i-\mathrm{Bu}$ \\
\hline 26 & Fellutamide derivative 2 & $\mathrm{C}_{27} \mathrm{H}_{53} \mathrm{~N}_{5} \mathrm{O}_{6}$ & 542.3914 & $\mathrm{C}_{11} \mathrm{H}_{23} \quad \mathrm{CH} 2 \mathrm{OH}$ & $i-\mathrm{Bu}$ \\
\hline 28 & Fellutamide derivative 4 & $\mathrm{C}_{28} \mathrm{H}_{53} \mathrm{~N}_{5} \mathrm{O}_{7}$ & 572.4018 & $\mathrm{C}_{10} \mathrm{H}_{21} \mathrm{CH}(\mathrm{OH}) \mathrm{CH}{ }_{2} \mathrm{H} 2 \mathrm{OH}$ & $i-\mathrm{Bu}$ \\
\hline
\end{tabular}

When comparing spectra of fellutamides B and C (12 and 13), there was a mass increment of $m / z=2$ in $[\mathrm{M}+\mathrm{H}]^{+} \mathrm{MS}^{1}$ ion, as well as in $\mathrm{MS}^{2}$ ions $\left[\mathrm{M}+\mathrm{H}-\mathrm{NH}_{3}\right]^{+},\left[\mathrm{M}+\mathrm{H}-\mathrm{H}_{2} \mathrm{O}\right]^{+}$and " $y$ " series of fragments, while the $\mathrm{MS}^{2}$ " $b$ " series of fragments shows the same nominal masses (Figure $\mathrm{S} 5 \mathrm{c}, \mathrm{d})$. This feature confirmed the same structure throughout the alkyl side chain, asparagine and glutamine residues, with a modification at the terminal leucinal residue that was reduced to a leucinol. Comparison of spectra from compounds $\mathbf{1 0}$ and $\mathbf{2 5}$ (Figure S5a,e) showed the exact same characteristics as observed for the pair of spectra 12 and 13, from which we deduced the structure of 25 as being the leucinol derivative of $\mathbf{1 0}$, thus identifying it as fellutamide derivative 1 . 
Compound 26 has the same nominal mass from $11(m / z=542)$, although both have different retention times and monoisotopic masses for $[\mathrm{M}+\mathrm{H}]^{+}(\mathbf{1 1}, m / z=542.3557 ; \mathbf{2 6}, \mathrm{m} / z=542.3914)$. HRMS monoisotopic mass indicated that the molecular formula of $\mathbf{2 6}$ differed from $\mathbf{1 1}$ by having one oxygen atom replaced by incorporation of one carbon and four hydrogens. Evaluation of $\mathrm{MS}^{2}$ spectra from 11 and 26 (Figure S5b,f) showed that there was a consistent pattern between them, with a decrease of $m / z=16$ in the " $b$ " series on the $\mathrm{MS}^{2}$ and an increase of $m / z=16$ in " $y$ " series of 26 . This difference indicated changes with the same overall $\mathrm{m} / \mathrm{z}$ occurring in the alkyl side chain and terminal amino acid residues, with loss of oxygen in the former and acquisition of carbon and hydrogens in the latter. The $\mathrm{MS}^{2}$ " $y$ " series ions in compound 26 matched the ones observed in compound 13, indicating the same terminal leucinol residue. HRMS $m / z$ from " $b$ " series MS ${ }^{2}$ ions in 26 indicated the absence of hydroxyl in the alkyl side chain. As such, we identified compound $\mathbf{2 6}$ as a novel saturated fatty acid fellutamide derivative 2 .

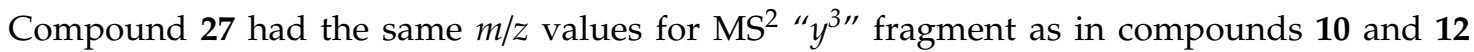
indicating the same asn-gln-leucinal residue (Figure S5g). Differences were observed in the MS ion $[\mathrm{M}+\mathrm{H}]^{+}$, as well as $\mathrm{MS}^{2}$ ions $\left[\mathrm{M}+\mathrm{H}-\mathrm{NH}_{3}\right]^{+},\left[\mathrm{M}+\mathrm{H}-\mathrm{H}_{2} \mathrm{O}\right]^{+}$and " $b$ " series fragments, with $m / z$ values for 27 showing an increase of $m / z=14$ when compared to 12, and a decrease of $m / z=14$ when matched to compound 10. As the difference between 10 and 12 relies on an extra $\mathrm{C}_{2} \mathrm{H}_{4}$ on the alkyl side chain, it is possible to infer that compound 27 possesses an intermediate alkyl side chain between them. The pair of $\mathrm{MS}^{2}$ spectra from 27 and 28 (Figure S5g,h) showed the same patterns observed for $\mathbf{1 2} / \mathbf{1 3}$ and $\mathbf{1 0} / \mathbf{2 5}$, indicating that 28 was the leucinol analog of $\mathbf{2 7}$. We, therefore, identified 27 as fellutamide derivative 3 , and 28 as fellutamide derivative 4 .

An intense $\left[\mathrm{M}+\mathrm{H}+\mathrm{H}_{2} \mathrm{O}\right]^{+}$peak in $\mathrm{MS}^{2}$ spectra of compounds 13, 25, 26, and 28 was observed and was indicative of a molecular structure that facilitates water loss during gas phase fragmentation, which further corroborates the presence of the reduced leucinol residue. To the best of our knowledge, molecules with structures 25-28 have not yet been described from natural sources. Moreover, we note that the $\mathrm{MS}^{2}$ spectra alone cannot determine with absolute certainty if alkane portions of these new fellutamides are linear, iso- or anteiso- alkanes.

In total, 28 molecules could be putatively identified by combining dereplication strategies using GNPS molecular network, database searches, literature comparisons of HRMS data from A. nidulans metabolites, molecular network evaluation, and manual curation of UPLC-HRMS/MS data (Figure 4).

The overall patterns of secondary metabolite expressed by the different A. pachycristatus strains were remarkably different, as evidenced by their chromatograms, but the patterns of metabolite production for the wt1, $\triangle A p c$.lae $A$ and $\triangle A p c . v e A$ strains were remarkably similar to those observed previously [12].

We observed various qualitative differences in metabolite expression in the mutants relative to their parent strain controls grown in the same conditions (Figure 1, Table S2). The laeA deletion mutant exhibited overall repression of secondary metabolite production that was consistent with our observations for NRRL 11440 [12] and for other Aspergillus species [14,16,17,33]. The veA mutant showed a more complex metabolite pattern, with repression of several metabolites such as aspercryptins. However, it also showed an increased production of other metabolites such emericellamide, and also the observation of metabolites not detected in wild types such as F9775-A and F-9775-B, a result consistent with previous observations in A. nidulans FGSC A4 [15]. For the mcrA mutant, a general increase of secondary metabolite production was observed, which parallels previous experiments with the same mutation in $A$. nidulans [18]. 
<smiles>Cc1cc(O)cc2oc(=O)c3c(O)cc(O)cc3c12</smiles>

(1)

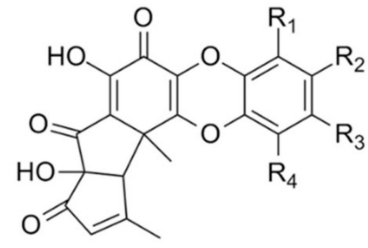

(2) $\mathrm{R}_{1}=\mathrm{OH}, \mathrm{R}_{2}=\mathrm{H}, \mathrm{R}_{3}=\mathrm{Me}, \mathrm{R}_{4}=\mathrm{H}$<smiles>CC(C)C[C@H]1NC(=O)[C@H](Cc2ccccc2)NC1=O</smiles>

(4)

(3) $\mathrm{R}_{1}=\mathrm{H}, \mathrm{R}_{2}=\mathrm{Me}, \mathrm{R}_{3}=\mathrm{H}, \mathrm{R}_{4}=\mathrm{OH}$<smiles>[R2]Oc1cc2c(c(O[R])c1OC/C=C(/C)CC/C=C(/C)CCC=C(C)C)CNC2=O</smiles><smiles>[R]C(=O)N[C@@H](CC(N)=O)C(=O)N[C@@H](CCC(N)=O)C(=O)NC([R2])[R]</smiles>

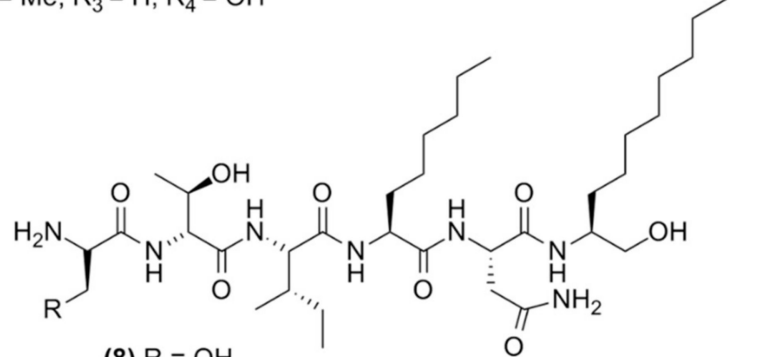

(8) $\mathrm{R}=\mathrm{OH}$

(9) $\mathrm{R}=\mathrm{H}$<smiles>[R]CCCCC([R])CC([R3])C(OC(=O)[C@H](C)NC(=O)[C@H](C)NC(=O)[C@H](CC(C)C)NC(=O)[C@H](NC(=O)CNC(=O)C(C)C)C([R])C([R])C)C(C)C</smiles>

(11) $\mathrm{R}_{1}=\mathrm{C}_{9} \mathrm{H}_{19} \mathrm{CH}(\mathrm{OH}) \mathrm{CH}_{2}, \mathrm{R}_{2}=\mathrm{CHO}, \mathrm{R}_{3}=i-\mathrm{Pr}$

(12) $\mathrm{R}_{1}=\mathrm{C}_{9} \mathrm{H}_{19} \mathrm{CH}(\mathrm{OH}) \mathrm{CH}_{2}, \mathrm{R}_{2}=\mathrm{CHO}, \mathrm{R}_{3}=i-\mathrm{Bu}$

(13) $\mathrm{R}_{1}=\mathrm{C}_{9} \mathrm{H}_{19} \mathrm{CH}(\mathrm{OH}) \mathrm{CH}_{2}, \mathrm{R}_{2}=\mathrm{CH}_{2} \mathrm{OH}, \mathrm{R}_{3}=i$ - $\mathrm{Bu}$

(14) $\mathrm{R}_{1}=\mathrm{H}, \mathrm{R}_{2}=\mathrm{H}, \mathrm{R}_{3}=\mathrm{CH}_{3}, \mathrm{R}_{4}=\mathrm{CH}_{3}$

(15) $R_{1}=H, R_{2}=H, R_{3}=H, R_{4}=C_{3}$ (Emericellamide C)

(25) $\mathrm{R}_{1}=\mathrm{C}_{9} \mathrm{H}_{19} \mathrm{CH}(\mathrm{OH}) \mathrm{CH}_{2}, \mathrm{R}_{2}=\mathrm{CH}_{2} \mathrm{OH}, \mathrm{R}_{3}=i-\mathrm{Bu}$ or $\mathrm{R}_{1}=\mathrm{H}, \mathrm{R}_{2}=\mathrm{H}, \mathrm{R}_{3}=\mathrm{CH}_{3}, \mathrm{R}_{4}=\mathrm{H}$ (Emericellamide $\mathrm{D}$ )

(26) $\mathrm{R}_{1}=\mathrm{C}_{11} \mathrm{H}_{23}, \mathrm{R}_{2}=\mathrm{CH}_{2} \mathrm{OH}, \mathrm{R}_{3}=i-\mathrm{Bu}$

(27) $\mathrm{R}_{1}=\mathrm{C}_{10} \mathrm{H}_{21} \mathrm{CH}(\mathrm{OH}) \mathrm{CH}_{2}, \mathrm{R}_{2}=\mathrm{CHO}, \mathrm{R}_{3}=i-\mathrm{Bu}$

(28) $\mathrm{R}_{1}=\mathrm{C}_{10} \mathrm{H}_{21} \mathrm{CH}(\mathrm{OH}) \mathrm{CH}_{2}, \mathrm{R}_{2}=\mathrm{CH}_{2} \mathrm{OH}, \mathrm{R}_{3}=i-\mathrm{Bu}$ 
likely to be produced by A. nidulans. In addition, the results from the molecular networking highlight its utility as a dereplication strategy to prioritize unknown metabolites for further evaluation.

\subsection{Confirmation of Homologous Gene Clusters in A. pachycristatus for the Identified Metabolites}

To understand how species-level phylogenetic divergence is reflected in divergence in secondary metabolism, we also compared the overall correspondence of secondary metabolic biosynthetic gene clusters (BGCs) between the strains of A. pachycristatus and A. nidulans (Figure 5, Table S4). At least 49 core biosynthetic genes showed high amino acid similarities $(>63 \%)$ between these two strains, of which 22 were PKS, 21 NRPS, 4 DMATS, 1 FAS, and 1 NRPS-like biosynthetic pathways. Furthermore, bioinformatic analysis indicated a capacity for each strain to encode BGCs unique to that strain. Aspergillus pachycristatus NRRL 11440 had 17 BGCs exclusive to its genome, while A. nidulans had 22. Thus, the two sibling species share approximately two-thirds of their respective secondary metabolite BGCs (Figure 5, Table S4). This degree of similarity was higher than between the sibling species pair of A. fumigatus and A. fishcheri where 10/33 of A. fumigatus BGCs are conserved in A. fischeri and only 13/48 A. fischeri BGCs are conserved in A. fumigatus [34].

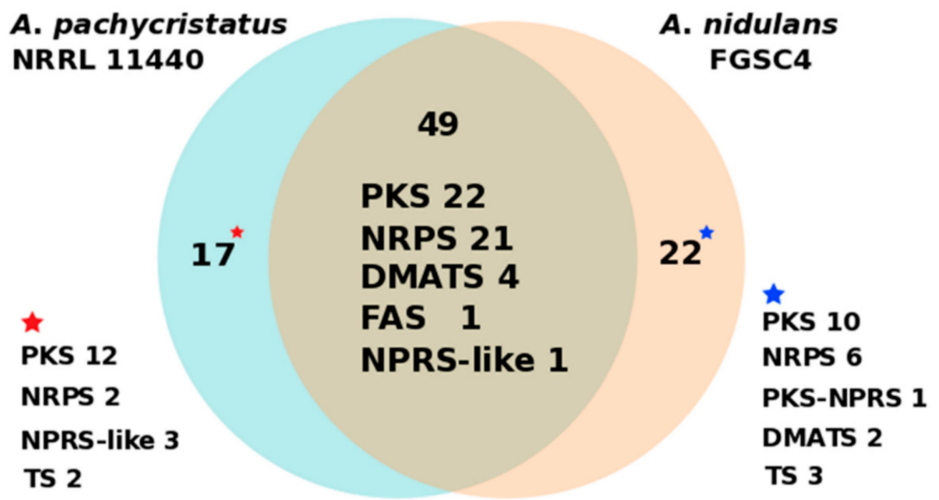

Figure 5. Numbers of distinct and shared secondary metabolite core catalytic genes between A. nidulans FGSC4 and A. pachycristatus NRRL 11440. PKS (polyketide synthase), NRPS (nonribosomal peptide synthetase), DMATS (dimethylallyltryptophan synthase), FAS (fatty acid synthase), and TS (terpene synthase).

Biosynthetic gene clusters in the genome of $A$. nidulans FGSC4 responsible for encoding the enzymes involved in the biosynthesis of targeted molecules were used as templates for searching homologous gene clusters in A. pachycristatus. Table 3 shows that for each identified secondary metabolite or metabolite family, the corresponding homologous gene cluster could be found in $A$. pachycristatus. The nonribosomal peptide synthetases (NRPSs) and polyketide synthases (PKSs) from each BGC homolog pair showed remarkably high amino acid similarity $(>79 \%)$ between these two species (Table 3 ). Thus, the genetic data confirmed that $A$. pachycristatus genome encodes the biosynthetic capacity for all the identified secondary metabolites.

Microsynteny of emericellamide, fellutamide, aspercryptin, aspernidine A, orsellinic acid/9775, and sterigmatocystin BGCs was analyzed between A. pachycristatus and A. nidulans (Figure S7). As expected, all the evaluated BGCs in A. pachycristatus consisted of close homologs of the genes encoding these molecules in $A$. nidulans, with a similar cluster organization and gene order which indicated a high degree of certainty that these set of BGCs are responsible for encoding the biosynthesis the metabolites listed in Table 3. 
Table 3. Core biosynthetic genes from inferred biosynthetic clusters for metabolites identified in Aspergillus pachycristatus and their homologs in A. nidulans.

\begin{tabular}{|c|c|c|c|c|c|}
\hline $\begin{array}{c}\text { Gene in A. pachycristatus } \\
\text { NRRL } 11440\end{array}$ & $\begin{array}{l}\text { Gene Name } \\
\text { A. Nidulans }\end{array}$ & $\begin{array}{l}\text { Corresponding } \\
\text { Gene FGSC A4 }\end{array}$ & Product & Type & $\underset{\%}{\operatorname{Similarity}}$ \\
\hline g7715 & $\operatorname{atn} A$ & AN7884 & Aspercryptin & NRPS & 92.2 \\
\hline g5866 & $e a s A$ & AN2545 & Emericellamide & NRPS & 91.1 \\
\hline g5867 & $e a s B$ & AN2547 & Emericellamide & PKS & 93.7 \\
\hline g7876 & $\operatorname{inp} A$ & AN3495 & Fellutamide & NRPS & 91.3 \\
\hline g7875 & $\operatorname{inpB}$ & AN3496 & Fellutamide & NRPS & 92.2 \\
\hline $\mathrm{g} 4770$ & sidD & AN6236 & $\mathrm{N}^{\prime}, \mathrm{N}^{\prime \prime}, \mathrm{N}^{\prime \prime \prime}$-triacetylfusarinine $\mathrm{C}$ & NRPS & 95.6 \\
\hline g8711 & ors $A$ & AN7909 & Orsellinic acid/F9775 & PKS & 93.2 \\
\hline $\mathrm{g} 4218$ & $p k f A$ & AN3230 & Aspernidine & PKS & 94.9 \\
\hline g5606 & $p k g A$ & AN7071 & Alternariol & PKS & 79.2 \\
\hline g7351 & stcA & AN7825 & Sterigmatocystin & PKS & 93.9 \\
\hline
\end{tabular}

These BGCs (Table 3) share a high identity and, in all but one instance (Figure S7), and the same gene order between the two strains. However, when we examined the gene cluster boundaries, adjacent genes, and genome loci of these BGCs between A. pachycristatus and A. nidulans, we unexpectedly found that the corresponding BGCs were located at different genome loci, even though they shared identical boundary genes in almost all cases. Thus, even in close sister species, the secondary metabolic gene clusters are inherited as independent units during the course of evolutionary time.

\section{Materials and Methods}

\subsection{Construction of Gene Deletion and Marker-Recycling Strains}

The basic strategy for gene disruption experiments and protoplast transformation methods were previously described in detail [12]. We disrupted the Apc.pyrG gene (orotidine-5'-phosphate decarboxylase, MK689400, AN6157 homologue) from NRRL 11440 by protoplast transformation to generate uracil-uridine auxotrophic strains [12]. To facilitate high recombination rates in the modified strain, the DNA double-strand break repair enzyme Apc.nkuA (ATP-dependent DNA helicase II, MK689401, AN7753 homolog) was inactivated by insertion of the selective marker pyr4 from Neurospora crassa. This strain was designated wt1. Neither substitution of the native Apc.pyrG gene with pyr4, or disruption of $A p c . n k u A$ appeared to affect colony morphology, sporulation, or secondary metabolism production [12].

For gene disruption, about $1 \mathrm{~kb}$ upstream and $1 \mathrm{~kb}$ downstream DNA exchange fragments of Apc.stcA or Apc.mcrA genes were fused into each end of afpyrG cassette by overlap PCR by using PrimeSTAR GXL DNA polymerase. Fusion DNA fragments were purified by QIAquick Gel Extraction Kit before use for protoplast transformation. After protoplast transformation of wt2 (for stcA deletion) or wt4 (for $m c r A$ deletion) (Table S3) strains, single-colonies were picked up and screened on MMS selection plates without uracil and uridine for at least three generations and then verified by diagnostic PCR (Figures S8 and S10). For pyrG marker recycling, about $1 \mathrm{~kb}$ upstream and $1 \mathrm{~kb}$ downstream DNA exchange fragments of $A p c . s t c A$ gene were cloned from wild type strain and fused together by overlap PCR. Purified fusion DNA fragments were used for protoplast transformation of wt3 strain. Positive transformants were screened on YAS medium supplemented with $1.0 \mathrm{mg} / \mathrm{mL}$ 5-FOA, $9 \mathrm{mM}$ uracil and $10 \mathrm{mM}$ uridine and verified by diagnostic PCR (Figure S9). Primers used for gene deletion, marker recycling, and diagnostic PCR are listed in Table S5. Thus, the wt 3 strain is identical to wt 1 strain, except that $A p c . s t c A$ was inactivated, thus abolishing sterigmatocystin production.

\subsection{Growth and Sample Preparation}

The medium for routine growth and sporulation was yeast extract medium (YAG, 1 L deionized $\mathrm{H} 2 \mathrm{O}), 5 \mathrm{~g}$ yeast extract, $10 \mathrm{~g}$ dextrose, $1 \mathrm{~mL}$ trace elements $(1000 \times$ stock), $2 \mathrm{~mL}$ vitamin mix $(500 \times$ stock), $10 \mathrm{~mL} 1 \mathrm{M} \mathrm{MgSO} 4 \cdot 7 \mathrm{H} 2 \mathrm{O}$ with or without $1.5 \%$ agar. To produce metabolites, strains were grown in 250-mL flasks containing $50 \mathrm{~mL}$ SMY medium (Bacto neopeptone $10 \mathrm{~g}$, maltose $40 \mathrm{~g}$, yeast 
extract $10 \mathrm{~g}$ per $1000 \mathrm{ml}$ of deionized $\mathrm{H}_{2} \mathrm{O}$ ). Cultures were maintained for 10 days at $24{ }^{\circ} \mathrm{C}$ and 220 $\mathrm{rpm}$. For the extraction procedure, an equal volume of ethyl acetate was added to the culture and the extraction carried out overnight, with agitation. The extract was vacuum-filtered, and the organic phase separated. A 5.0-mL aliquot was placed in a clean glass flask and evaporated to dryness at $37^{\circ} \mathrm{C}$ under gentle airflow. The dried extract was reconstituted in $0.25 \mathrm{~mL}$ of acetonitrile, diluted with $0.25 \mathrm{~mL}$ of ultra-pure water, filtered through $0.22 \mu \mathrm{m} \mathrm{RC}$ membrane and submitted to chromatographic analyses.

\subsection{HPLC-MS Analysis}

HPLC-MS data were acquired on an Agilent 1260 HPLC equipped with a diode array detector (DAD) and coupled to an Agilent 6120 single quadrupole mass spectrometer (MS), with an Ace Equivalence $5 \mathrm{C}_{18}, 4.6 \times 150 \mathrm{~mm}, 5 \mu \mathrm{m}$ column kept at $30{ }^{\circ} \mathrm{C}$. The pump used a binary solvent system consisting of $0.1 \%$ aqueous formic acid (solvent $\mathrm{A}$ ) and, $0.1 \%$ formic acid in acetonitrile (ACN) (solvent B) with the following gradient: $20 \%-100 \%$ B for 22 min, and maintaining $100 \% \mathrm{~B}$ for $4 \mathrm{~min}, 1.0$ $\mathrm{mL} \cdot \mathrm{min}^{-1}$. The chromatographic profiles were monitored by wavelength scanning from 190 to $400 \mathrm{~nm}$ and by positive and negative ESI-MS from $m / z 160-1500$. The injection volume was $10 \mu \mathrm{L}$.

\subsection{UPLC-HRMS Analysis}

Extracts were analyzed with a Waters Acquity I-Class UPLC with DAD detector and equipped with an Acquity UPLC BEH C18 $(1.7 \mathrm{um}, 2.1 \times 50 \mathrm{~mm})$ at $40{ }^{\circ} \mathrm{C}$, with flow rate of $0.5 \mathrm{~mL} \cdot \mathrm{min}^{-1}$. The following gradient was applied using $0.1 \%$ aqueous acetic acid (solvent $\mathrm{A}$ ) and $0.1 \%$ acetic acid in $\mathrm{ACN}$ (solvent B): at 0 min., $5 \% \mathrm{~B}$, maintained for $2 \mathrm{~min}, 14 \mathrm{~min}, 95 \% \mathrm{~B}$. The column eluent was directed to a Thermo Orbitrap mass spectrometer, operating in the 100-1000 mass range, using as heat temp 375 ${ }^{\circ} \mathrm{C}$, sheath gas flow rate 45, Aux Gas Flow Rate 10, Sweep Gas Flow Rate 3, I Spray Voltage $4.10 \mathrm{kV}$, Capillary Temp $320^{\circ} \mathrm{C}$, S-Lens RF Level 55\%. The injection volume was $2 \mu \mathrm{L}$.

\subsection{Metabolic Profiling, Molecular Networking and Compound Dereplication}

Chromatograms were analyzed with Thermo Xcalibur software for the identification of peaks, measurements of individual peak height, and accurate $\mathrm{MS}^{1} \mathrm{~m} / \mathrm{z}$.

Raw data from UPLC-HRMS/MS were converted to mzXML using ProteoWizard (version 3.0.10051, Vanderbilt University, USA). All mzXML data were uploaded to the Global Natural Products Social Networking (GNPS) website (https:/gnps.ucsd.edu/ProteoSAFe/static/gnps-splash.jsp). A molecular network was created using the online workflow at the GNPS. The data were filtered by removing all MS/MS peak $\backslash \mathrm{s}$ within $+/-17$ Da of the precursor $m / z$. MS/MS spectra were window filtered by choosing only the top six peaks in the +/- 50 Da window throughout the spectrum. The data was then clustered with MS-Cluster with a parent mass tolerance of $0.02 \mathrm{Da}$ and a MS/MS fragment ion tolerance of $0.02 \mathrm{Da}$ to create consensus spectra. Furthermore, consensus spectra that contained less than one spectra were discarded. A network was then created where edges were filtered to have a cosine score above 0.7 and more than four matching peaks. Edges between two nodes were kept in the network if, and only if, each of the nodes appeared in each other's respective top 10 most similar nodes. The spectra in the network were then searched against the GNPS spectral libraries. The library spectra were filtered in the same manner as the input data. All matches kept between network spectra and library spectra were required to have a score above 0.7 and at least six matched peaks. Analog searching was enabled against the library with a maximum mass shift of $0.02 \mathrm{Da}$ [4]. The metabolic network was built using Cytoscape 3.7.0 [35]. The job ID is ID = 5b9e80c94f054e0d91f194be81594019.

Dereplication of known molecules was enabled by matching to hits in GNPS database and aided by manually searching other databases such as the Natural Product Atlas (www.npatlas.org/) and the Dictionary of Natural Products (dnp.chemnetbase.com/). Moreover, due to the genetic similarities of $A$. pachycristatus and A. nidulans secondary metabolism, previous works describing A. nidulans metabolites were used as proxy set $[28,31,36-43]$. 
3.6. Comparison of Secondary Metabolic Biosynthestic Gene Clusters of A. pachycristatus NRRL 11440 and A. nidulans FGSC A4

The genetically encoded BGCs of A. pachycristatus NRRL 11440 were predicted by submitting the unannotated scaffold sequences for antiSMASH analysis (https://fungismash.secondarymetabolites. org/) $[44,45]$ and by reciprocal BLAST searches of predicted proteins and annotated scaffolds with sequences of previously determined core genes and gene clusters from A. nidulans [37,38,42,43,46-48] followed by manual correction of some incorrectly predicted ORFs. Orthologous biosynthetic gene clusters between $A$. pachycristatus NRRL 11440 and $A$. nidulans FGSC A4 were aligned and illustrated using Easyfig [49] to determine gene identity (\%) and microsynteny.

\section{Conclusions}

By referencing an extensively explored and annotated model organism as a proxy, we were able to efficiently dereplicate several gene clusters and classes of previously undescribed metabolites from mutant strains of $A$. pachycristatus. Collectively, the results of this study confirm that $A$. pachycristatus shares roughly two-thirds of secondary biosynthetic gene clusters and metabolites with that of $A$. nidulans. However, it still produces or has the potential to produce a large set of yet unknown secondary metabolites and biosynthetic genes that can be further explored as a potential source for the discovery of novel molecules. Moreover, we confirmed the possibility of expanding the observed metabolome of $A$. pachycristatus through the disruption of global regulator genes. The metabolic effects of gene disruptions in $A$. pachycristataus (lae $A, v e A, m c r A$ ) approximately paralleled reported effects in $A$. nidulans. These results provide additional evidence that these gene disruptions can be a useful tool to enhance and vary overall secondary metabolite expression and enabling the discovery of silent and cryptic metabolites.

Supplementary Materials: The following are available online at http://www.mdpi.com/1420-3049/25/4/913/s1, Figure S1. Morphological variations in Aspergillus pachycristatus mutants grown on agar media. Figure S2. Extracted ion chromatogram $\left(\mathrm{EIC}^{+}=m / z\right.$ 1042-1044) from LC-MS analysis of Aspergillus pachycristatus strains in SYM media highlighting the production of echinocandin $\mathrm{B}\left[\mathrm{M}+\mathrm{H}-\mathrm{H}_{2} \mathrm{O}\right]^{+}$ion in all tested media. Figure S3. A) $\mathrm{MS}^{1}$; B) $\mathrm{MS}^{2}$ and C) Proposed fragmentation pathway of $\mathrm{N}^{\prime} \mathrm{N}^{\prime}, \mathrm{N}^{\prime \prime}$-Triacetylfusarinine C. Figure S4. A) $\mathrm{MS}^{1}$; B) $\mathrm{MS}^{2}$ and C) Proposed fragmentation pathway of $\mathrm{N}, \mathrm{N}^{\prime}, \mathrm{N}^{\prime \prime}$-Triacetylfusarinine $\mathrm{C}$ analog containing an extra methylene. Blue fragments indicates $\mathrm{m} / \mathrm{z}$ similar to those observed in TAFC, while orange $\mathrm{m} / \mathrm{z}$ represent fragments containing an increased $14 \mathrm{Da}$. Figure S5. Chromatogram and $\mathrm{MS}^{1}$ spectra showing other possible analogs of $\mathrm{N}_{1} \mathrm{~N}^{\prime}, \mathrm{N}^{\prime \prime}$-Triacetylfusarinine $\mathrm{C}(22,23)$ containing extra methylene units, when compared to $N, N^{\prime}, N^{\prime \prime}$-Triacetylfusarinine $C(21)$ and their putative structure. Figure S6. MS ${ }^{1}$ and $\mathrm{MS}^{2}$ HRMS spectra of fellutamides: (a) Antibiotic 1656G (10); (b) Antibiotic 3127 (11); (c) Fellutamide B (12); (d) Fellutamide C (13); (e) Fellutamide derivative 1 (25); (f) Fellutamide derivative 2 (26); (g) Fellutamide derivative 3 (27); (h) Fellutamide derivative 4 (28). Figure S7. Microsynteny comparisons of emericellamide, fellutamide, aspercryptin, aspernidine A, orsellinic acid/9775 and sterigmatocystin BGCs between A. pachycristatus NRRL 11440 and A. nidulans FGSC A4. Figure S8. Construction of DNA fusion fragments for apc.stcA deletion and diagnostic PCR. A. Schematic diagram of Apc.stcA disruption by insertion of Af.pyrG as selective marker gene by homologous recombination. B. Agarose gel images of PCR products of construction of DNA fusion fragments for protoplast transformation. C. Schematic diagram of verification of $\triangle A p c$.stcA transformants. D. Agarose gel images of PCR products for detection of Apc.stcA deletion of eight independent transformants. Figure S9. Recycling of Af.pyrG marker gene from $\triangle A p c . s t c A$ mutant. A. Schematic diagram of Af.pyrG deletion from Apc.stcA locus and verification of Af.pyrG recycling transformants. B. Agarose gel images of PCR products of construction of DNA fusion fragments for protoplast transformation and PCR products for detection of Af.pyrG deletion of 10 independent transformants Figure S10. Construction of DNA fusion fragments for $\triangle A p c$.mcrA deletion and diagnostic PCR. A. Schematic diagram of Apc.mcrA disruption by insertion of Af.pyrG as selective marker gene by homologous recombination. B. Agarose gel images of PCR products of construction of DNA fusion fragments for protoplast transformation. C. Schematic diagram of verification of $\triangle A p c . m c r A$ transformants. D. Agarose gel images of PCR products for detection of Apc.mcrA deletion transformants. Table S1. HRMS error for diagnostic MS and $\mathrm{MS}^{2}$ ions for fellutamides. Table S2. Qualitative evaluation of the presence of detected metabolites in the extracts of A. pachycristatus strains. Table S4. Correspondence of secondary metabolic BGCs between strains A. pachycristatus NRRL 11440 and A. nidulans FGSC A4. Table S5. Primers used in this study.

Author Contributions: Conceptualization, B.P., L.N., G.B.; methodology, B.P., L.N., G.B.; investigation, B.P., L.N., Y.J., G.B.; resources, Y.J., Z.A., G.B.; data curation, B.P., L.N.; writing-original draft preparation, B.P., L.N., G.B.; 
writing—review and editing, B.P., L.N., G.B.; supervision, Z.A., G.B.; funding acquisition, Z.A., G.B. All authors have read and agreed to the published version of the manuscript.

Funding: Portions of this work were supported by Cidara Therapeutics.

Acknowledgments: The authors are grateful to Cidara Therapeutics for the supporting with the genome sequencing of Aspergillus pachycristatus NRRL 11440.

Conflicts of Interest: The authors declare no conflict of interest.

\section{References}

1. Tormo, J.R.; Asensio, F.J.; Bills, G.F. Manipulating filamentous fungus chemical phenotypes by growth on nutritional arrays. Methods Mol. Biol. 2012, 944, 59-78. [CrossRef] [PubMed]

2. Bouslimani, A.; Sanchez, L.M.; Garg, N.; Dorrestein, P.C. Mass spectrometry of natural products: current, emerging and future technologies. Nat. Prod. Rep. 2014, 31, 718-729. [CrossRef] [PubMed]

3. El-Elimat, T.; Figueroa, M.; Ehrmann, B.M.; Cech, N.B.; Pearce, C.J.; Oberlies, N.H. High-resolution MS, MS/MS, and UV database of fungal secondary metabolites as a dereplication protocol for bioactive natural products. J. Nat. Prod. 2013, 76, 1709-1716. [CrossRef] [PubMed]

4. Wang, M.; Carver, J.J.; Phelan, V.V.; Sanchez, L.M.; Garg, N.; Peng, Y.; Nguyen, D.D.; Watrous, J.; Kapono, C.A.; Luzzatto-Knaan, T.; et al. Sharing and community curation of mass spectrometry data with Global Natural Products Social Molecular Networking. Nat. Biotechnol. 2016, 34, 828-837. [CrossRef] [PubMed]

5. Chen, A.J.; Frisvad, J.C.; Sun, B.D.; Varga, J.; Kocsube, S.; Dijksterhuis, J.; Kim, D.H.; Hong, S.B.; Houbraken, J.; Samson, R.A. Aspergillus section Nidulantes (formerly Emericella): Polyphasic taxonomy, chemistry and biology. Stud. Mycol. 2016, 84,1-118. [CrossRef] [PubMed]

6. Tóth, V.; Nagy, C.T.; Miskei, M.; Pócsi, I.; Emri, T. Polyphasic characterization of "Aspergillus nidulans var. roseus" ATCC 58397. Folia. Microbiol. (Praha) 2011, 56, 381-388. [CrossRef] [PubMed]

7. Boeck, L.D. New antibiotics: Antifungals from Aspergillus. In Frontiers in Industrial Mycology; Leatham, G., Ed.; Chapman \& Hall: New York, NY, USA, 1992; pp. 54-65.

8. Boeck, L.D.; Kastner, R.E. Method of producing the A-30912 antibiotics. U.S. Patent 4,288,549, 21 January 1981.

9. Emri, T.; Majoros, L.; Toth, V.; Pocsi, I. Echinocandins: Production and applications. Appl. Microbiol. Biotechnol. 2013, 97, 3267-3284. [CrossRef]

10. Andersen, M.R.; Nielsen, J.B.; Klitgaard, A.; Petersen, L.M.; Zachariasen, M.; Hansen, T.J.; Blicher, L.H.; Gotfredsen, C.H.; Larsen, T.O.; Nielsen, K.F.; et al. Accurate prediction of secondary metabolite gene clusters in filamentous fungi. Proc. Natl. Acad. Sci. USA 2013, 110, E99-E107. [CrossRef]

11. De Vries, R.P.; Riley, R.; Wiebenga, A.; Aguilar-Osorio, G.; Amillis, S.; Uchima, C.A.; Anderluh, G.; Asadollahi, M.; Askin, M.; Barry, K.; et al. Comparative genomics reveals high biological diversity and specific adaptations in the industrially and medically important fungal genus Aspergillus. Genome Biol. 2017, 18, 28. [CrossRef]

12. Lan, N.; Yue, Q.; An, Z.; Bills, G.F. Apc.LaeA and Apc.VeA of the velvet complex govern secondary metabolism and morphological development in the echinocandin-producing fungus Aspergillus pachycristatus. J. Ind. Microbiol. Biotechnol. 2019. [CrossRef]

13. Bayram, O.; Braus, G.H. Coordination of secondary metabolism and development in fungi: the velvet family of regulatory proteins. FEMS Microbiol. Rev. 2012, 36, 1-24. [CrossRef] [PubMed]

14. Bok, J.W.; Keller, N.P. LaeA, a regulator of secondary metabolism in Aspergillus spp. Eukaryot Cell 2004, 3, 527-535. [CrossRef] [PubMed]

15. Bok, J.W.; Soukup, A.A.; Chadwick, E.; Chiang, Y.M.; Wang, C.C.; Keller, N.P. VeA and MvlA repression of the cryptic orsellinic acid gene cluster in Aspergillus nidulans involves histone 3 acetylation. Mol. Microbiol. 2013, 89, 963-974. [CrossRef] [PubMed]

16. Kale, S.P.; Milde, L.; Trapp, M.K.; Frisvad, J.C.; Keller, N.P.; Bok, J.W. Requirement of LaeA for secondary metabolism and sclerotial production in Aspergillus flavus. Fungal. Genet. Biol. 2008, 45, 1422-1429. [CrossRef] [PubMed]

17. Lind, A.L.; Smith, T.D.; Saterlee, T.; Calvo, A.M.; Rokas, A. Regulation of secondary metabolism by the velvet complex is temperature-responsive in Aspergillus. G3 Genes Genomes Genetics 2016, 6, 4023-4033. [CrossRef] [PubMed] 
18. Oakley, C.E.; Ahuja, M.; Sun, W.W.; Entwistle, R.; Akashi, T.; Yaegashi, J.; Guo, C.J.; Cerqueira, G.C.; Russo Wortman, J.; Wang, C.C.; et al. Discovery of McrA, a master regulator of Aspergillus secondary metabolism. Mol. Microbiol. 2017, 103, 347-365. [CrossRef] [PubMed]

19. De la Cruz, M.; Martin, J.; Gonzalez-Menendez, V.; Perez-Victoria, I.; Moreno, C.; Tormo, J.R.; El Aouad, N.; Guarro, J.; Vicente, F.; Reyes, F.; et al. Chemical and physical modulation of antibiotic activity in emericella species. Chem. Biodivers 2012, 9, 1095-1113. [CrossRef]

20. Schrettl, M.; Bignell, E.; Kragl, C.; Sabiha, Y.; Loss, O.; Eisendle, M.; Wallner, A.; Arst, H.N., Jr.; Haynes, K.; Haas, H. Distinct roles for intra- and extracellular siderophores during Aspergillus fumigatus infection. PLoS Pathog. 2007, 3, 1195-1207. [CrossRef]

21. De Lorenzo, V.; Bindereif, A.; Paw, B.H.; Neilands, J.B. Aerobactin biosynthesis and transport genes of plasmid ColV-K30 in Escherichia coli K-12. J. Bacteriol. 1986, 165, 570-578. [CrossRef]

22. Martin, J.D.; Ito, Y.; Homann, V.V.; Haygood, M.G.; Butler, A. Structure and membrane affinity of new amphiphilic siderophores produced by Ochrobactrum sp. SP18. J. Biol. Inorg. Chem. 2006, 11, 633-641. [CrossRef]

23. McMahon, M.D.; Rush, J.S.; Thomas, M.G. Analyses of MbtB, MbtE, and MbtF suggest revisions to the mycobactin biosynthesis pathway in Mycobacterium tuberculosis. J. Bacteriol. 2012, 194, 2809-2818. [CrossRef] [PubMed]

24. Chen, J.; Guo, Y.; Lu, Y.; Wang, B.; Sun, J.; Zhang, H.; Wang, H. Chemistry and biology of siderophores from narine microbes. Mar. Drugs 2019, 17, 562. [CrossRef] [PubMed]

25. Haas, H. Fungal siderophore metabolism with a focus on Aspergillus fumigatus. Nat. Prod. Rep. 2014, 31, 1266-1276. [CrossRef] [PubMed]

26. Hilder, R.C.; Kong, X. Chemistry and biology of siderophores. Nat. Products Rep. 2010, 27, 637-657. [CrossRef]

27. Renshaw, J.C.; Robson, G.D.; Trinci, A.P.J.; Wiebe, M.G.; Livens, F.R.; Collison, D.; Taylor, R.J. Fungal siderophores: Structures, functions and applications. Mycol. Res. 2002, 106, 1123-1142. [CrossRef]

28. Lee, Y.M.; Dang, H.T.; Hong, J.; Lee, C.O.; Bae, K.S.; Kim, D.K.; Jung, J.H. A cytotoxic lipopeptide from the sponge-derived fungus Aspergillus versicolor. Bull. Korean Chem. Soc. 2010, 31, 205-208. [CrossRef]

29. Lee, Y.M.; Dang, H.T.; Li, J.; Zhang, P.; Hong, J.; Lee, C.O.; Jung, J.H. A cytotoxic fellutamide analogue from the sponge-derived fungus Aspergillus versicolor. Bull. Korean Chem. Soc. 2011, 32, 3817-3820. [CrossRef]

30. Shigemori, H.; Wakuri, S.; Yazawa, K.; Nakamura, T.; Sasaki, T.; Kobayashi, J.I. Fellutamides A and B, cytotoxic peptides from a marine fish-possessing fungus Penicillium fellutanum. Tetrahedron 1991, 47, 8529-8534. [CrossRef]

31. Xu, D.; Ondeyka, J.; Harris, G.H.; Zink, D.; Kahn, J.N.; Wang, H.; Bills, G.; Platas, G.; Wang, W.; Szewczak, A.A.; et al. Isolation, structure, and biological activities of fellutamides $C$ and $D$ from an undescribed Metulocladosporiella (Chaetothyriales) using the genome-wide Candida albicans fitness test. J. Nat. Prod. 2011, 74, 1721-1730. [CrossRef]

32. Wu, C.J.; Li, C.W.; Cui, C.B. Seven new and two known lipopeptides as well as five known polyketides: The activated production of silent metabolites in a marine-derived fungus by chemical mutagenesis strategy using diethyl sulphate. Mar. Drugs 2014, 12, 1815-1838. [CrossRef]

33. Bok, J.W.; Hoffmeister, D.; Maggio-Hall, L.A.; Murillo, R.; Glasner, J.D.; Keller, N.P. Genomic mining for Aspergillus natural products. Chem. Biol. 2006, 13, 31-37. [CrossRef] [PubMed]

34. Mead, M.E.; Knowles, S.L.; Raja, H.A.; Beattie, S.R.; Kowalski, C.H.; Steenwyk, J.L.; Silva, L.P.; Chiaratto, J.; Ries, L.N.A.; Goldman, G.H.; et al. Characterizing the pathogenic, genomic, and chemical traits of Aspergillus fischeri, a close relative of the major human fungal pathogen Aspergillus fumigatus. mSphere 2019, 4. [CrossRef] [PubMed]

35. Shannon, P.; Markiel, A.; Ozier, O.; Baliga, N.S.; Wang, J.T.; Ramage, D.; Amin, N.; Schwikowski, B.; Ideker, T. Cytoscape: a software environment for integrated models of biomolecular interaction networks. Genome Res. 2003, 13, 2498-2504. [CrossRef] [PubMed]

36. Albright, J.C.; Henke, M.T.; Soukup, A.A.; McClure, R.A.; Thomson, R.J.; Keller, N.P.; Kelleher, N.L. Large-scale metabolomics reveals a complex response of Aspergillus nidulans to epigenetic perturbation. ACS Chem. Biol. 2015, 10, 1535-1541. [CrossRef] 
37. Chiang, Y.M.; Szewczyk, E.; Nayak, T.; Davidson, A.D.; Sanchez, J.F.; Lo, H.C.; Ho, W.Y.; Simityan, H.; Kuo, E.; Praseuth, A.; et al. Molecular genetic mining of the Aspergillus secondary metabolome: discovery of the emericellamide biosynthetic pathway. Chem. Biol. 2008, 15, 527-532. [CrossRef]

38. Henke, M.T.; Soukup, A.A.; Goering, A.W.; McClure, R.A.; Thomson, R.J.; Keller, N.P.; Kelleher, N.L. New aspercryptins, lipopeptide natural products, revealed by HDAC inhibition in Aspergillus nidulans. ACS Chem. Biol. 2016, 11, 2117-2123. [CrossRef]

39. Nielsen, K.F.; Larsen, T.O. The importance of mass spectrometric dereplication in fungal secondary metabolite analysis. Front. Microbiol. 2015, 6, 71. [CrossRef]

40. Oh, D.C.; Kauffman, C.A.; Jensen, P.R.; Fenical, W. Induced production of emericellamides A and B from the marine-derived fungus Emericella sp. in competing co-culture. J. Nat. Prod. 2007, 70, 515-520. [CrossRef]

41. Scherlach, K.; Schuemann, J.; Dahse, H.M.; Hertweck, C. Aspernidine A and B, prenylated isoindolinone alkaloids from the model fungus Aspergillus nidulans. J. Antibiot. (Tokyo) 2010, 63, 375-377. [CrossRef]

42. Yaegashi, J.; Praseuth, M.B.; Tyan, S.W.; Sanchez, J.F.; Entwistle, R.; Chiang, Y.M.; Oakley, B.R.; Wang, C.C. Molecular genetic characterization of the biosynthesis cluster of a prenylated isoindolinone alkaloid aspernidine A in Aspergillus nidulans. Org. Lett. 2013, 15, 2862-2865. [CrossRef]

43. Yeh, H.H.; Ahuja, M.; Chiang, Y.M.; Oakley, C.E.; Moore, S.; Yoon, O.; Hajovsky, H.; Bok, J.W.; Keller, N.P.; Wang, C.C.; et al. Resistance gene-guided genome mining: Serial promoter exchanges in Aspergillus nidulans reveal the biosynthetic athway for fellutamide B, a proteasome inhibitor. ACS Chem. Biol. 2016, 11, 2275-2284. [CrossRef] [PubMed]

44. Blin, K.; Wolf, T.; Chevrette, M.G.; Lu, X.; Schwalen, C.J.; Kautsar, S.A.; Suarez Duran, H.G.; de Los Santos, E.L.C.; Kim, H.U.; Nave, M.; et al. antiSMASH 4.0-improvements in chemistry prediction and gene cluster boundary identification. Nucleic. Acids. Res. 2017, 45, W36-W41. [CrossRef] [PubMed]

45. Weber, T.; Blin, K.; Duddela, S.; Krug, D.; Kim, H.U.; Bruccoleri, R.; Lee, S.Y.; Fischbach, M.A.; Muller, R.; Wohlleben, W.; et al. antiSMASH 3.0-a comprehensive resource for the genome mining of biosynthetic gene clusters. Nucleic. Acids. Res. 2015, 43, W237-W243. [CrossRef] [PubMed]

46. Brown, D.W.; Yu, J.H.; Kelkar, H.S.; Fernandes, M.; Nesbitt, T.C.; Keller, N.P.; Adams, T.H.; Leonard, T.J. Twenty-five coregulated transcripts define a sterigmatocystin gene cluster in Aspergillus nidulans. Proc. Natl. Acad. Sci. USA 1996, 93, 1418-1422. [CrossRef] [PubMed]

47. David, H.; Özçelik, I.Ş.; Hofmann, G.; Nielsen, J. Analysis of Aspergillus nidulans metabolism at the genome-scale. BMC Genomics 2008, 9. [CrossRef] [PubMed]

48. Sanchez, J.F.; Chiang, Y.M.; Szewczyk, E.; Davidson, A.D.; Ahuja, M.; Elizabeth Oakley, C.; Woo Bok, J.; Keller, N.; Oakley, B.R.; Wang, C.C. Molecular genetic analysis of the orsellinic acid/F9775 gene cluster of Aspergillus nidulans. Mol. Biosyst. 2010, 6, 587-593. [CrossRef]

49. Sullivan, M.J.; Petty, N.K.; Beatson, S.A. Easyfig: A genome comparison visualizer. Bioinformatics 2011, 27, 1009-1010. [CrossRef]

Sample Availability: Samples of the crude extracts are available from the authors.

(C) 2020 by the authors. Licensee MDPI, Basel, Switzerland. This article is an open access article distributed under the terms and conditions of the Creative Commons Attribution (CC BY) license (http://creativecommons.org/licenses/by/4.0/). 